\title{
Intervenção Psicológica a Gestantes: Contribuições do Grupo de Suporte para a Promoção da Saúde
}

Psycological pregnants' intervention: support group contributions for health promotion

Intervención psicológica a gestantes: contribuciones del grupo de soporte para la promoción de la salud

Michele Moreira de

Souza Klein \& Carla Ribeiro Guedes

Faculdades Integradas Maria Thereza

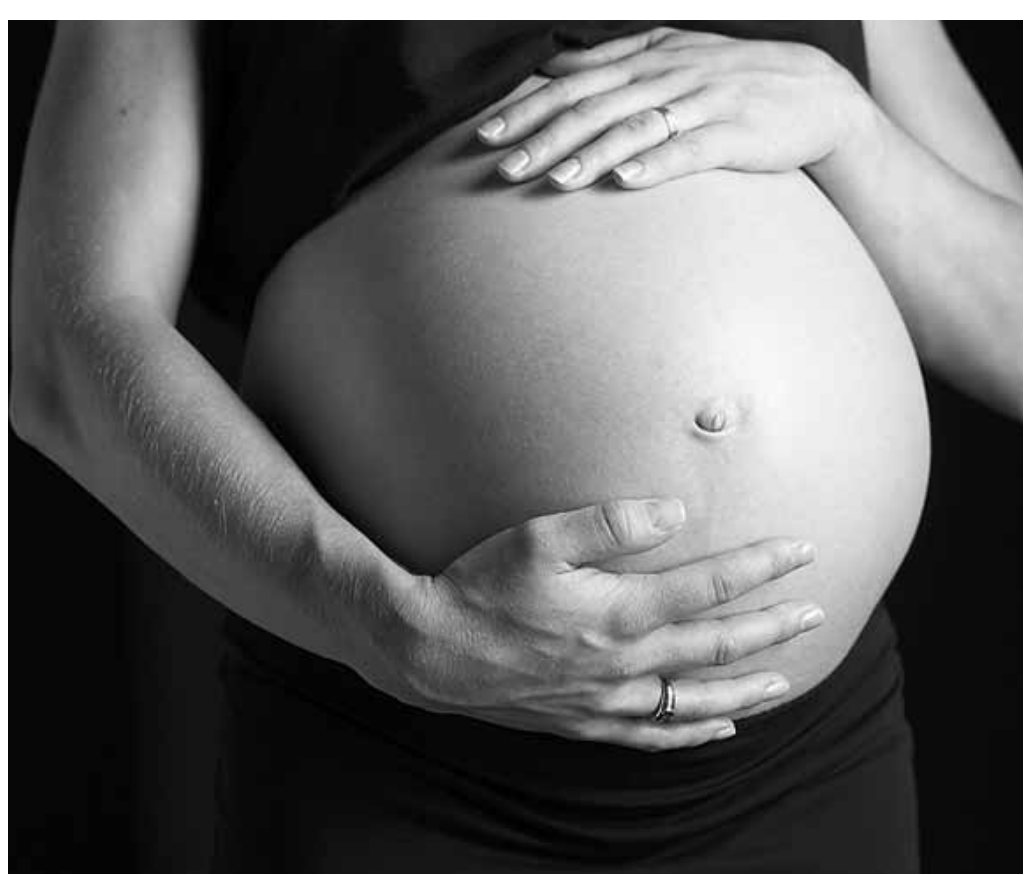


Resumo: O presente artigo visa a apresentar um modo de o psicólogo atuar com gestantes, utilizando princípios do grupo de suporte. A intervenção grupal procurou promover a saúde da mulher que passa por essa fase vital, criando um espaço para compartilharem reflexões e informações acerca das mudanças que atravessam. A metodologia consistiu no relato da experiência ocorrida num hospital privado, no Município de Resende. Foram realizados 22 encontros. Para orientar o trabalho, cada encontro previa três momentos: apresentações, discussão do tema através de palestra interativa e momento de avaliação. Como resultados, constatamos que a identificação entre as gestantes, o compartilhar sentimentos e o apoio mútuo funcionaram como suporte social. Concluímos que o grupo constituiu uma intervenção primária, à medida que tomou uma postura de promoção da saúde, atingindo os níveis de atuação psicoterapêutico, psicopedagógico e psicoprofilático.

Palavras-chave: Gestantes. Grupo de suporte. Intervenção primária. Promoção da saúde.

Abstract: The present article aims at showing a psychologist treatment with pregnant women using the support group principles. This treatment attempted to promote the health of the women who are in this vital phase, creating a space to share their reflections and informations concerning the changes in this period. The methodology consisted in one experienced description that happened in a private hospital in ResendeRJ. There were 22 meetings and in each of them there were specific moments: presentations, discussion of the topic by an interactive talk and an evaluation moment. As results, we verified that the identification between the pregnant women, the feelings shared and the mutual support functioned as social supports. We concluded that the group constituted a primary intervention and reached the levels of psychotherapeutic, psycopedagogic and psycoprophylactic actuation.

Keywords: Pregnants. Support group. Primary intervention. Promotion of the health.

Resumen: El presente artículo pretende presentar un modo para que el psicólogo actué con gestantes, utilizando principios del grupo de soporte. La intervención de grupo buscó promover la salud de la mujer que pasa por esa fase vital, creando un espacio para que compartan ponderaciones e informaciones acerca de los cambios que atraviesan. La metodología consistió en el relato de la experiencia ocurrida en un hospital privado, en el Municipio de Resende. Fueron realizados 22 encuentros. Para orientar el trabajo, cada encuentro preveía tres momentos: presentaciones, discusión de la tema a través de exposición interactiva y momento de evaluación. Como resultados, constatamos que la identificación entre las gestantes, compartirlo sentimientos y el apoyo mutuo funcionaron como soporte social. Concluimos que el grupo constituyó una intervención primaria, a la medida que tomó una postura de promoción de la salud, alcanzando los niveles de actuación psicoterapéutico, psicopedagógico y psicoprofiláctico.

Palabras-clave: Gestantes. Grupo de soporte. Intervención primaria. Promoción de la salud.

O presente artigo tem a intenção de apresentar um modo de o psicólogo atuar com gestantes, utilizando princípios e fundamentos práticos do grupo de suporte. A intervenção com o grupo de gestantes foi realizada em um hospital privado, no Município de Resende, Estado do Rio de Janeiro, e teve como objetivo promover a saúde da mulher que passa por essa fase vital.

Entendemos que a mulher está vulnerável durante a gestação, exposta a múltiplas exigências, e vivencia um período de reorganização corporal, bioquímica, hormonal, familiar e social que a faz ficar propensa a uma multiplicidade de sentimentos (Falcone, Mader, Nascimento, Santos, \& Nóbrega, 2005). A ansiedade é um componente emocional que pode acompanhar todo o período gestacional e é caracterizada por um estado de insatisfação, insegurança, incerteza e medo da experiência desconhecida (Baptista, Baptista \& Torres, 2006).

Dessa forma, a gestação é um período que envolve grandes mudanças biopsicossociais, ou seja, há transformações não só no organismo da mulher mas também no seu bem-estar, o que altera seu psiquismo e o 
Maldonado (1988) ressalta que a gravidez é uma transição que faz parte do processo de desenvolvimento e envolve a necessidade de reestruturação em várias dimensões; uma delas é a mudança de identidade e a nova definição de papéis. seu papel sociofamiliar. A intensidade das alterações psicológicas dependerá de fatores familiares, conjugais, sociais, culturais e da personalidade da gestante. Como aponta Soifer (1992), deve-se levar em conta o fato de ser a gravidez um período que envolve não apenas a mulher mas também o seu companheiro e o seu meio social imediato.

A mudança do papel social é outro fator importante a ponderar. Durante nove meses, estará se instalando no casal "grávido" uma nova identidade. Deixarão de ser apenas filhos para se tornarem também pais. Maldonado (1988) ressalta que a gravidez é uma transição que faz parte do processo de desenvolvimento e envolve a necessidade de reestruturação em várias dimensões; uma delas é a mudança de identidade e a nova definição de papéis.

A gestação, portanto, compreende uma lenta evolução em nível de transformações. Em contrapartida, o parto é um processo abrupto, caracterizado por mudanças rápidas (Chiattone, 2006). A mulher o teme como algo desconhecido, doloroso e também como momento inaugural de concretude da relação mãe-filho; teme também o papel de mãe por este ser mitificado e conter a exigência de a mãe ser um modelo de perfeição. Com todas essas exigências, a gestante chega ao parto, muitas vezes, sem refletir sobre seus desejos, suas possibilidades e suas limitações (Pamplona, 1990).

Maldonado (1988) afirma que situar a gravidez como transição não significa que o período crítico termine com o parto, pois grande parte das mudanças maturacionais ocorre após a mulher dar à luz, e, dessa forma, o puerpério deve ser considerado a continuação do período de transformação, pois implica modificações fisiológicas assim como da rotina e do relacionamento familiar. Sendo assim, entendemos que é relevante um acompanhamento psicológico da gestante com o intuito de possibilitar uma vivência mais equilibrada de todas as emoções e manifestações que ocorrem durante o ciclo gravídico-puerperal. Nesse sentido, a intervenção em grupo pode tornar-se um meio eficaz para esse acompanhamento, pois permite a identificação entre seus membros, o compartilhar de experiências e a troca de informações.

A informação, mesmo clara, objetiva e adequada, não é em si suficiente para a sensibilização pessoal. Ela passa, necessariamente, pelo crivo das representações sociais, dos sentidos e dos significados já existentes. Nessa perspectiva, os trabalhos realizados em grupo podem constituir-se em meios facilitadores para a ocorrência de reflexão e da tomada de consciência de aspectos importantes envolvidos no dia a dia das pessoas que normalmente passam despercebidos por elas. Busca-se, assim, o envolvimento das emoções e sentimentos junto às cognições. Além disso, o trabalho grupal implementado de modo criativo e adequado proporciona uma atmosfera de aceitação e ânimo para discussão e reflexão sobre novas atitudes perante as questões apresentadas (Silva, 2002).

Desse modo, o grupo pode ser entendido como espaço de compartilhamento e coconstrução de sentidos. Ao se tomar a produção de sentidos como processo dialógico, a intervenção grupal tem por objetivo facilitar a emergência de novas percepções sobre fatos e acontecimentos, a clarificação dos valores e o exercício do respeito à diferença. É a diferença que permite o encontro e o reconhecimento da identidade. São esses os pilares para a aprendizagem de novos papéis sociais, inclusive o de ser mãe. Os grupos possibilitam às gestantes ressignificar a experiência social e exercitar o respeito a si próprias e ao outro (Silva, 2002). 
Concordamos com Delfino, Patrício, Martins e Silvério (2004) quando destacam que as possibilidades de saúde integral na gestação consistem nos recursos individuais e coletivos que existem no contexto da gestante e do seu bebê, e podem estar relacionados ao atendimento das suas necessidades, e também quando reiteram que a promoção da saúde é um processo realizado pelo profissional de saúde junto às gestantes com vistas a conscientizá-las a fim de que se tornem participantes ativas nas decisões que envolvem a sua gestação e de que promovam transformações das suas limitações em possibilidades de viver saudável.

Assim, um grupo de suporte a gestantes pode proporcionar discussões que envolvam vários componentes afetivos, possibilitando um clima de sensibilização para os aspectos relativos ao ciclo gravídico-puerperal e à subjetivação das informações bem como uma vivência positiva da gestação, do parto e da maternidade.

Procuramos criar um espaço de reflexão sobre as diversas mudanças que atravessam a gestação, trocar informações objetivas sobre o ciclo gravídico-puerperal, proporcionar um espaço grupal de discussão dos diferentes aspectos que envolvem a gravidez, o parto, o puerpério e os cuidados com um filho recém-nascido, possibilitar a expressão e o compartilhar de sentimentos e auxiliar na elaboração dessa situação de vida que pode se tornar problemática quer seja pelas intercorrências orgânicas, quer pelas subjetivas.

\section{Método}

Para a organização dos encontros grupais com gestantes, utilizamos os princípios e os fundamentos práticos do grupo de suporte, cujo principal objetivo é promover a coesão e o apoio entre os membros, a fim de elevar a auto-estima e a autoconfiança dos mesmos. Sua principal finalidade é terapêutica, pois procura aliviar ou eliminar sintomas, desenvolver comportamentos saudáveis e proporcionar um aprendizado nas relações interpessoais. Troca afetiva, cuidado, comunicação e constância são suas bases (Campos, 2000).

Foram realizados 22 encontros grupais com gestantes, no período de julho de 2006 a junho de 2007. As sessões ocorreram quinzenalmente, com 90 min. de duração, nas dependências do Serviço de Psicologia Hospitalar de um hospital privado, de pequeno porte, no Município de Resende, Estado do Rio de Janeiro.

Os encontros foram transcritos com o consentimento das gestantes, e os relatos foram analisados qualitativamente a partir das contribuições teóricas de Muniz e Taunay (2000), Campos (2000), Graça, Burd e Mello Filho (2000), Romano (1999) e Silva (2002).

Fizeram parte do trabalho gestantes entre 19 e 40 anos, de variadas idades gestacionais, sendo de duas a oito mulheres a população de grávidas atendidas em cada encontro. No total, 25 gestantes passaram pelo grupo, 18 primíparas e 7 multíparas. Apenas 10 tiveram uma freqüência mais contínua, isto é, participaram de mais de 8 encontros dos 22 realizados. Três motivos levaram 15 gestantes a participarem de menos de 8 encontros: 2 sofreram aborto espontâneo, 8 deram à luz e 5 não compareceram mais ao grupo por decisão própria.

O grupo de gestantes foi aberto, pois as participantes não eram fixas. Apesar de não existir um compromisso rígido de freqüência e permanência - característica de um grupo aberto -, ressaltamos para as gestantes a importância de comparecerem a todos os encontros que pudessem, a fim de possibilitar a formação de vínculos estáveis entre as participantes e a coordenadora do grupo. 
O trabalho teve início a partir do convite feito pelo Serviço de Psicologia Hospitalar, através de telefonemas, já que uma das médicas obstetras do hospital fornecia uma relação com os nomes das suas pacientes e seus respectivos telefones, e também por meio de convites impressos, deixados no consultório dos demais médicos obstetras e nas recepções do hospital.

O planejamento previa, em cada encontro, três momentos, geralmente com o uso de técnicas de dinâmicas de grupo: a) apresentação da coordenadora, da proposta de trabalho e das participantes; b) introdução e discussão do tema feito através de "palestra interativa", ou seja, a articulação das opiniões trazidas pelo grupo, a partir de suas experiências, com informações acerca da temática em questão; c) momento de relaxamento e avaliação do encontro.

Esse planejamento teve a intenção de orientar o trabalho sem que fosse, no entanto, rígido. Ao contrário, foi preciso contar com os imprevistos, por exemplo, relativos à disponibilidade e à aceitação do grupo quanto às técnicas ou quanto à atividade de relaxamento. O planejamento, portanto, era flexível.

O desenvolvimento dos temas foi realizado por meio de palestras interativas, deixando claro para as gestantes a possibilidade de se colocarem quando ou sempre que sentissem necessidade, acrescentando experiências, opiniões e esclarecendo dúvidas. Esses temas foram: aspectos psicológicos da gravidez, alimentação na gestação, amamentação e cuidados com o recém-nascido, tipos de parto e anestesia, comunicação intra-uterina entre mãe e bebê, a gravidez e os mitos da maternidade, aspectos psicológicos do pósparto, depressão pós-parto e sexualidade na gravidez. Alguns temas, como tipos de parto, sexualidade na gravidez e depressão pós-parto, foram discutidos mais de uma vez.

Os encontros eram sempre planejados acompanhando os temas de interesse colocados pelas gestantes no grupo. As participantes sugeriam a temática para o próximo encontro, que refletia os medos e os anseios pelos quais elas estavam passando. A tabela 1 apresenta a relação dos temas trabalhados, os objetivos e as respectivas técnicas de dinâmica de grupo utilizadas. 
Tabela 1. Seqüência dos temas discutidos nos encontros

\begin{tabular}{|c|c|c|}
\hline Tema & Objetivos & Técnicas \\
\hline Apresentação & $\begin{array}{l}\text { Promover o conhecimento grupal, } \\
\text { integrar, descontrair, criar um clima } \\
\text { de trabalho. }\end{array}$ & $\begin{array}{l}\text { Minha característica é...(a } \\
\text { participante se apresenta de um } \\
\text { modo bem inusitado, utilizando } \\
\text { uma palavra, que pode ser um } \\
\text { objeto, sentimento ou adjetivo); } \\
\text { berlinda (cada participante fica em } \\
\text { lugar de destaque e as outras lhe } \\
\text { formulam perguntas). }\end{array}$ \\
\hline
\end{tabular}

Aspectos psicológicos da gestação

Alimentação na gestação

Amamentação e cuidados com o recém-nascido

Tipos de parto e anestesia

Comunicação intra-uterina entre mãe e bebê

A gravidez e os mitos da maternidade

Aspectos psicológicos do pós-parto

Depressão pós-parto

Sexualidade na gestação
Facilitar para que as gestantes falassem das suas vivências atuais; apresentar os aspectos emocionais de cada trimestre da gestação.

Estimular a alimentação saudável.

Orientar quanto ao ato de amamentar e cuidar do bebê e mostrar a importância da amamentação.

Levantar o universo referencial das gestantes sobre a temática; minimizar o medo das gestantes de não saberem reconhecer os sinais do trabalho de parto; apresentar os tipos de parto.

Apresentar as vias de comunicação entre mãe e filho durante a gravidez: fisiológica, empática e comportamental; fortalecer a relação mãe-bebê.

Refletir sobre os sentimentos contraditórios da gestação, que muitas vezes divergem do imaginário social.

Facilitar para que as participantes se conheçam, refletindo sobre o que observam, o que pensam e o que sentem a respeito das mudanças do pós-parto.

Informar sobre as enfermidades depressivas classificadas no período pós-parto: blues puerperal, depressão pós-parto e psicose puerperal.

Orientar e esclarecer dúvidas.
Abrindo janelas, que consta de frases incompletas redigidas em cartelas, por exemplo: "A emoção que mais dificuldade sinto de controlar é..."

Nutricionista convidada

Enfermeira convidada

Três palavras, que consiste em escrever as três primeiras palavras que vêm à mente ao verem o termo parto escrito em um cartão.

Palestra interativa

Cartelas preenchidas com algumas frases que correspondem a mitos sociais sobre a maternidade.

Estrela de cinco pontas, que consiste no desenho grande de uma estrela; no seu centro é escrito pós-parto, e, em cada extremidade, o que se observa, o que se pensa, o que é sentido, como gostaria que fosse, e o que é feito com relação ao tema.

Depoimentos

Três perdas e três ganhos da gestação. 
Gérbera' disse, ao $3^{\circ}$ mês de gestação: "Sintome confortada em saber que as outras gestantes também têm alterações". Jasmim, ao $4^{\circ}$ mês de gestação, falou: "Consegui perceber que tem mais pessoas que passam pelo que eu estou passando".

$1 \quad \mathrm{C}$ o m $\quad \mathrm{a}$ finalidade de pr seus nomes foram substituídos por nomes de flores.
No terceiro momento do encontro, a atividade de relaxamento, com músicas específicas, teve a intenção de desenvolver e/ ou reforçar o vínculo mãe-bebê e de propiciar bem-estar físico e psíquico. Iniciava-se com um exercício de respiração; em seguida, era orientado que percebessem cada parte do corpo, desde os pés até a face. Por último, que colocassem as mãos sobre a barriga e entrassem em contato com o bebê, sentissem seus movimentos, se dispusessem afetivamente para ele, dessem a ele carinho e atenção. A atividade era finalizada com outro exercício de respiração.

Para realizar as intervenções grupais, a coordenação assumia uma postura altamente ativa, apoiadora e acolhedora; estimulava a fala e a expressão dos sentimentos das participantes, favorecendo a livre discussão e a comunicação interpessoal, clarificava os pontos importantes, marcando as dificuldades verbalizadas, dinamizava o debate dos temas, oferecia continente aos conteúdos trazidos, mantinha as intervenções em torno da situação-foco e estimulava a pessoa a buscar recursos de enfrentamento mais amadurecidos. Além disso, procurava manter um clima emocional favorável e de apoio entre os membros, ou seja, não incitava conflitos nem competição (que podiam aparecer) e estimulava a coesão grupal.

\section{Resultados e discussão}

A partir da transcrição realizada dos encontros e das avaliações que as participantes faziam ao fim de cada encontro, constatamos os resultados alcançados nas intervenções grupais às gestantes.

Observamos que o grupo de suporte favoreceu o surgimento de fatores terapêuticos citados por Muniz e Taunay (2000). A coesão, ou seja, a união entre as participantes, foi um desses fatores. Por estarem juntas e discutindo questões em comum, houve uma grande identificação entre elas.
As gestantes também perceberam que não estavam sós, pois puderam observar que passam ou já passaram por problemas semelhantes, o que contribuiu para a presença do fator universalidade de conflitos, citado por Muniz e Taunay (2000), como ilustram as falas abaixo: Gérbera ${ }^{1}$ disse, ao $3^{\circ}$ mês de gestação: "Sinto-me confortada em saber que as outras gestantes também têm alterações". Jasmim, ao 4o mês de gestação, falou: "Consegui perceber que tem mais pessoas que passam pelo que eu estou passando".

Identificamos também o desenvolvimento do sentimento de altruísmo, mencionado por Muniz e Taunay (2000). Os membros do grupo que se sentem apoiados entre si têm mais condições de serem coesos e solidários. A possibilidade de se encontrarem regularmente e o estímulo às trocas afetuosas, por meio da criação e da manutenção de vínculos interpessoais, complementam o clima de coesão e apoio, como exemplificam os depoimentos a seguir: "Você vai ficar bem, a gente vai te ajudar" (Bromélia disse para Gérbera, depois que esta expôs sua frustração em descobrir que estava grávida e seu medo de voltar a ter crises de síndrome do pânico como na primeira gestação); Tulipa disse, ao 4o mês de gestação: "O que mais aprendi nesses encontros foi que sempre podemos ajudar o próximo com nossas experiências".

O grupo de suporte também proporcionou momentos de catarse, mencionado pelos autores Muniz e Taunay (2000), ou seja, as gestantes se sentiram à vontade para desabafar, chorar e expressar verbalmente seus sentimentos e problemas: "O grupo, para mim, foi de extrema importância, pois pude expor questões pessoais", disse Orquídea, com cinco meses de gestação. "O grupo serve como um apoio para nós gestantes, um lugar para desabafar e falar de assuntos de interesse em comum", afirmou Violeta, no 7ํ mês.

A aprendizagem interpessoal, citada também pelos autores Muniz e Taunay (2000), e 
a troca de informações objetivas sobre o ciclo gravídico-puerperal foram fatores que permearam todos os encontros, proporcionando mais segurança e maior conscientização sobre os aspectos que envolvem a gestação, o parto e o puerpério, como pode ser verificado nas falas a seguir: "Para mim, participar do grupo foi muito bom, pois conheci novas pessoas e aprendi coisas que não sabia", falou Begônia, já no 8o mês. "O encontro foi produtivo; apesar de já ter um filho, sempre há dúvidas que nesse encontro esclarecemos. Sei que iremos um pouco mais preparadas para o parto", afirmou Tulipa.

As pessoas reunidas em torno de uma situação comum sentem-se imediatamente identificadas, ressalta Campos (2000). Compartilham angústias e esperanças, limitações e discriminações, prescrições e recomendações semelhantes. Vimos que a troca de cuidados e informações fluiu com vigor no grupo: "O grupo é muito importante, pois pude ajudar outras gestantes com minha experiência", ressaltou Tulipa. "O encontro foi um momento de partilha de experiências, dúvidas e alegrias", disse Bromélia, ainda no 2o mês de gestação.

O suporte social oferecido pelo grupo atuou reforçando o self, e, com isso, cada gestante sentiu-se melhor consigo mesma, conscientizando-se dos fatores que envolvem o período gestatório. Dessa forma, observamos a elevação da auto-estima e da autoconfiança das participantes. Esse fato, aponta Campos (2000), aumenta a disposição da pessoa de se cuidar, de se sentir bem, de viver a vida; ela se aceita melhor, se valoriza mais e confia mais nos próprios recursos, o que está expresso nos depoimentos de Dália e Íris: "O grupo traz tranqüilidade, ajuda a manter a calma e diminui a ansiedade", expressou Dália, já no 8o mês. "No grupo, sinto tranqüilidade, segurança e fico mais confiante", disse Íris, no 5ํ mês de gestação.

Podemos observar que o trabalho de intervenção com grupo de gestantes atingiu resultados expressivos, à medida que serviu como dispositivo de suporte social e promoveu a coesão e o apoio entre as participantes. Além disso, possibilitou benefícios como os apresentados por Romano (1999), como a percepção de que não estavam sós, o compartilhar sentimentos com pessoas na mesma situação, a redução da ansiedade, melhor compreensão e maior controle cognitivo da situação que estavam atravessando.

O grupo de suporte a gestantes também contemplou as características descritas por Graça, Burd e Mello Filho (2000): serviu como continente, à medida que ofereceu um espaço para os conteúdos e para as angústias das participantes, propiciou o holding, cuidando e dando suporte e possibilitou a função de pensar, isto é, favoreceu a reflexão dos indivíduos sobre suas experiências emocionais, idéias e sentimentos.

A experiência trazida por parte de cada gestante funcionou como estímulo, quando se constatou que outras têm ou tiveram as mesmas dificuldades e que, de algum modo, conseguiram superá-las. Funcionou também como suporte, quando alguém demonstrou medo e angústia e recebeu das demais o apoio necessário para não esmorecer.

Constatamos que o trabalho com grupo de gestantes atingiu os três níveis de atuação do profissional de Psicologia apontados por Romano (1999): psicopedagógico, psicoprofilático e psicoterapêutico.

Na dimensão pedagógica, o grupo se constituiu em um espaço para fazer circular a palavra social, no qual a informação foi levada não como uma verdade absoluta, mas como algo que devia ser socializado. Foi preciso articular reflexão e experiência para evitar a alienação do conhecimento tomado como uma verdade absoluta e neutra. Foi isso que buscamos com as "palestras interativas", nas quais as 
informações deveriam ser contextualizadas na experiência. A livre discussão também teve efeito pedagógico, no sentido de educar a participante a ouvir o que as outras tinham a dizer e de buscar, por meio da fala, expressar e defender suas idéias.

Na sua dimensão terapêutica, os fatores que estavam em jogo na ação do grupo foram o apoio por meio de relações afetuosas, cuidadoras e empáticas mantidas entre todos, a identificação e a troca de experiências, o espaço para expressão de sentimentos e o espaço para informação e reflexão acerca dos aspectos que envolvem o ciclo gravídicopuerperal. Esses fatores proporcionaram suporte social e levaram ao reforço do self das participantes. Com isso, elas se sentiram melhor, tiveram a auto-estima e a autoconfiança elevadas, desenvolveram comportamentos mais saudáveis e reduziram a ansiedade. A possibilidade dada a cada uma de expressar livremente suas idéias e seus sentimentos teve excelente efeito catártico e organizador do pensamento, permitindo compreensões que a gestante não tivera até então.

Quanto à dimensão psicoprofilática, Romano (1999) assinala que é preciso privilegiar o ato sanitário de natureza preventiva e educativa, de abrangência coletiva, fundado mais na promoção e na proteção da saúde do que no tratamento. Dentro dessa perspectiva, Silva (2002) ressalta que as estratégias de prevenção e promoção da saúde tanto em níveis individuais como sociocomunitários devem ser prioritárias.

Sendo assim, cabe pontuar que o trabalho com o grupo de gestantes consistiu em uma prevenção primária, e teve o propósito de prepará-las para viver o momento do parto de maneira mais segura e tranqüila, tornandose, em algumas ocasiões, um trabalho que se sobrepôs a uma pura profilaxia, assumindo uma postura de promoção da saúde.
Podemos dizer que esse trabalho não trouxe "garantias" de uma passagem tranqüila e saudável pelo parto, pois as experiências de parto na vida da mulher e também na de sua família podem influir na sua maneira de pensar, sentir e até vivenciar o próximo parto, podendo ser, em parte, compensadas pela preparação ocorrida no grupo, mas não totalmente anuladas.

No entanto, o trabalho permitiu às gestantes maior compreensão do que estavam vivendo em nível emocional e orgânico, e, a partir disso, sentiram-se mais capazes de experienciar todo o processo de gestação de modo ativo. Além disso, elas puderam expressar dúvidas, ambivalências, angústias, receios, dificuldades e preocupações, o que propiciou alívio e encorajamento para o enfrentamento da realidade de ter um filho.

\section{Comentários finais}

Apresentar um modo de atuação do psicólogo com gestantes, utilizando princípios e fundamentos práticos do grupo de suporte, constituiu a meta deste artigo. Essa intervenção com o grupo de suporte a gestantes buscou promover a saúde da mulher que passa pela fase da gestação.

O grupo atuou na subjetividade das gestantes, tentando levá-las a mudanças comportamentais e intrapsíquicas, isto é, a transformações necessárias e suficientes para permitir que elas lidassem melhor com a fase da gestação. Sendo assim, foi na subjetividade dessas mulheres que percebemos como o trabalho com o grupo de suporte foi produtivo, no sentido de vê-las mais autoconfiantes e dispostas para o enfrentamento da realidade. Ocorreram também repercussões na forma pessoal de a gestante se avaliar e avaliar o que ocorre ao seu redor, ou seja, na sua auto-estima. 
Acreditamos ser o ambiente de grupo, em especial o do grupo de suporte, o espaço privilegiado para que a gestante se sinta estimulada a enveredar pelo caminho do resgate da saúde, que passa, antes, pelo resgate de sua auto-estima.

Sendo assim, o trabalho veio complementar a assistência pré-natal naquele hospital, promovendo a saúde das participantes e o fortalecimento da relação e da comunicação entre as gestantes e a equipe obstétrica.
Concordamos com Gomes e Guedes (2004) quando ressaltam que as possibilidades de trabalho com gestantes são ilimitadas, apesar de, no Brasil, as iniciativas, a partir de uma abordagem de prevenção e promoção da saúde, continuarem elementares. Por isso, é muito relevante empreender ações como esta, que possam descobrir ou abrir caminhos a outras, a fim de contribuir para melhor assistência às mulheres na vivência da maternidade.

\section{Michele Moreira de Souza Klein*}

Psicóloga, pós-graduada do curso de Especialização em Psicologia, Subjetividade e Instituições de Saúde pelas Faculdades Integradas Maria Thereza, Niterói-RJ

\section{Carla Ribeiro Guedes}

Orientadora do estudo, psicóloga, doutora em Saúde Coletiva pelo Instituto de Medicina Social da Universidade do Estado do Rio de Janeiro, professora do Curso de Psicologia da Universidade Estácio de Sá, Campus ResendeRJ, e do Curso de Pós-Graduação em Psicologia, Subjetividade e Instituições de Saúde das Faculdades Integradas Maria Thereza, Niterói-RJ

*Endereço para envio de correspondência:

Rua Euzébio Manoel da Glória, 215 Bairro Itapuca - Resende - RJ - Brasil CEP: 27524-250

E-mail: psi.michele@oi.com.br

Recebido 06/11/2007 Reformulado 28/08/2008 Aprovado 30/08/2008

Referências
Baptista, M. N., Baptista, A. S. D., \& Torres, E. C. R. (2006). Associação entre suporte social, depressão e ansiedade em gestantes. Revista de Psicologia da Vetor Editora, 7(1), 39-48.

Campos, E. P. (2000). Grupos de suporte. In J. Mello Filho (Ed.), Grupo e corpo: psicoterapia de grupo com pacientes somáticos (pp. 117-130). Porto Alegre: Artes Médicas.

Chiattone, H. B. C. (2006). Psicologia e obstetrícia. Trabalho apresentado no XIII Congresso Brasileiro de Psicologia Hospitalar, UNIP, São Paulo.

Delfino, M. R. R., Patrício, Z. M., Martins, A. S., \& Silvério, M. R. (2004). O processo de cuidar participante com um grupo de gestantes: repercussões na saúde integral individual-coletiva. Ciência \& Saúde Coletiva, 9(4), 1057-1066.

Falcone, V. M., Mader, C. V. N., Nascimento, C. F. L., Santos, J. M. M., \& Nóbrega, F. J. (2005). Atuação multiprofissional e a saúde mental de gestantes. Revista Saúde Pública, 39(4), 333-340.

Gomes, L. A., \& Guedes, C. R. (2004). A preparação para o parto como prevenção primária com grupos de sala de espera: a experiência de trabalho interprofissional. Revista Psicologia Hospitalar, 2(2).
Graça, L. A. C. Burd, M., \& Mello Filho, J. (2000). Grupos com diabéticos. In J. Mello Filho (Ed.), Grupo e corpo: psicoterapia de grupo com pacientes somáticos (pp. 257-267). Porto Alegre: Artes Médicas.

Maldonado, M. T. P. (1988). Psicologia da gravidez, parto e puerpério. Petrópolis, RJ: Vozes.

Muniz, J. R., \& Taunay, M. (2000). Grupos de enfermaria no hospital geral. In J. Mello Filho Grupo e corpo: psicoterapia de grupo com pacientes somáticos (pp. 145-162). Porto Alegre: Artes Médicas.

Pamplona, V. (1990). Mulher, parto e psicodrama (2a ed.) São Paulo: Agora.

Romano, B. W. (1999). Princípios para a prática da Psicologia clínica em hospitais. São Paulo: Casa do Psicólogo.

Silva, R. C. (2002). Metodologias participativas para trabalhos de promoção de saúde e cidadania. São Paulo: Vetor.

Soifer, R. (1992). Psicologia da gravidez, parto e puerpério (6a ed.). Porto Alegre: Artes Médicas. 